\title{
From Zero- to One-Dimensional, Opportunities and Caveats of Hybrid lodobismuthates for Optoelectronic Applications
}

\author{
Alla Skorokhod, ${ }^{1}$ Nicolas Mercier, ${ }^{1, *}$ Magali Allain, ${ }^{1}$ Matthieu Manceau, ${ }^{2}$ Claudine Katan, ${ }^{3}$ \\ and Mikaël Kepenekian ${ }^{3, \neq}$ \\ ${ }^{1}$ MOLTECH-Anjou, UMR-CNRS 6200, Université d'Angers, 49045 Angers, France \\ ${ }^{2}$ Department of Solar Technologies, INES, CEA, LITEN, Université Grenoble Alpes, F-73375 Le Bourget du Lac, France \\ ${ }^{3}$ Univ Rennes, ENSCR, INSA Rennes, CNRS, ISCR - UMR 6226, F-35000 Rennes, France
}

Emails: nicolas.mercier@univ-angers.fr; mikael.kepenekian@univ-rennes1.fr

The association of the electron acceptor 4,4'-amino-bipyridinium $\left(\mathrm{AmV}^{2+}\right)$ dication and $\mathrm{Bil}_{3}$ in an acidic solution affords three organic-inorganic hybrid materials, $(\mathrm{AmV})_{3}\left(\mathrm{Bil}_{6}\right)_{2}(1),(\mathrm{AmV})_{2}\left(\mathrm{Bi}_{4} \mathrm{l}_{16}\right)(2)$, and $(\mathrm{AmV}) \mathrm{Bil}_{5}$ (3), whose structures are based on isolated $\mathrm{Bil}_{6}{ }^{3-}$ and $\mathrm{Bi}_{4} \mathrm{l}_{16}{ }^{4-}$ anion clusters in 1 and 2, respectively, and on a one-dimensional (1D) chain of trans-connected corner-sharing octahedra in 3. In contrast with known methylviologen-based hybrids, these compounds are more soluble in polar solvents, allowing thin film formation by spin-coating. (AmV)Bil ${ }_{5}$ exhibits a broad absorption band in the visible region leading to an optical bandgap of $1.54 \mathrm{eV}$ and shows a PV effect as demonstrated by a significant open-circuit voltage close to $500 \mathrm{mV}$. The electronic structure of the three compounds has been investigated using first-principles calculations based on density functional theory (DFT). Unexpectedly, despite the trans-connected cornershared octahedra, for $(\mathrm{AmV}) \mathrm{Bil}_{5}$, the valence state shows no coupling along the wire direction, leading to a high effective mass for holes, while in contrast, the strong coupling between Bi $6 p x$ orbitals in the same direction at the conduction band minimum suggests excellent electron transport properties. This contributes to the low current output leading to the low efficiency of perovskite solar cells based on $(\mathrm{AmV})$ Bil $_{5}$. Further insight is provided for trans- and cis- $\mathrm{Ml}_{5}$ 1D model structures $(\mathrm{M}=\mathrm{Bi}$ or $\mathrm{Pb}$ ) based on $\mathrm{DFT}$ investigations.

\section{Introduction}

Perovskite solar cells (PSCs) represent a new generation of photovoltaics, combining the advantages of lowtemperature thin film processing (the process costing less than half of the price of c-Si solar cell technology) ${ }^{1,2}$ and a high power conversion efficiency (PCE), currently reaching $25.5 \% .{ }^{3}$ However, the more efficient solar cells contain a high percentage (>30\%) of the toxic $\mathrm{Pb}$ element, which could prevent its industrial development. Several strategies have been considered for substituting the $\mathrm{Pb}^{2+}$ ion with an environmentally friendly element, all of the corresponding compounds being known as lead-free perovskites. The first strategy was to substitute $\mathrm{Pb}^{2+}$ with a homovalent element, mainly $\mathrm{Sn}^{2+}$. If $\mathrm{Sn}$-based PSCs were obtained with quite high efficiencies, ${ }^{4}$ the replacement of $\mathrm{Pb}$ with $\mathrm{Sn}$ also showed undesirable effects such as the toxicity of $\mathrm{Sn}^{5}$ and the severe instability to air and moisture of tin halide perovskites. The second strategy was to use heterovalent 
elements, mainly $\mathrm{Bi}^{3+}$ and $\mathrm{Sb}^{3+}$, leading to two main categories of materials. ${ }^{6-8}$ The first category is known as double perovskites. To maintain a three-dimensional (3D) structure, the mixed cation approach consisting of

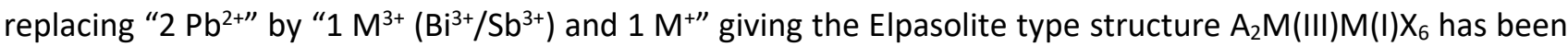
successfully developed. ${ }^{9-11}$ One challenge for such materials is the preparation of high-quality thin films even if, quite recently, a process that affords a nice thin film of $\mathrm{Cs}_{2} \mathrm{AgBiBr}_{6}$ leading to a PCE of $2.84 \%$ that constitutes a record for such a double perovskite has been reported. ${ }^{9}$ The second category consists of hybrids based on iodobismuthate or iodoantimonate anions. Depending on the nature, size, and charge of the organic cations, many different types of such anions, resulting from corner-, edge-, or face-sharing $\mathrm{MI}_{6}(\mathrm{M}=\mathrm{Bi}$ or $\mathrm{Sb})$ octahedra, are known. ${ }^{12}$ Unfortunately, most of these anions are of the cluster type, ${ }^{13-15}$ which lead to low structural and electronic dimensionalities for the corresponding materials. They also lead to modest power conversion efficiencies; for instance, the past record efficiency of lead-free perovskites was reached with $\mathrm{CS}_{3} \mathrm{Bi}_{2} \mathrm{l}_{9} \mathrm{clusters}$, with an efficiency of slightly $>1 \%\left(0.6 \mathrm{FF}, 0.85 \mathrm{~V}\right.$, and $\left.2.15 \mathrm{~mA} \mathrm{~cm}{ }^{-2}\right) .{ }^{16}$ While some one-dimensional (1D) and two-dimensional (2D) non-perovskite networks have also been reported, such as the well-known $1 \mathrm{D} \mathrm{Bil}{ }_{4}$ chain of edge-sharing octahedra, ${ }^{17} 1 \mathrm{D}$ and 2D perovskite networks (having octahedra in corner-sharing mode only) are rarer. One $\mathrm{Bi} / \mathrm{I} 2 \mathrm{D}$ perovskite network $\mathrm{Bi}_{2 / 3} \mathrm{l}_{4}{ }^{-}$(Bi-deficient monolayer, $n=1$, of the $\langle 100\rangle$-oriented family $)^{18}$ was reported 20 years ago, ${ }^{19}$ while in recent years, $2 \mathrm{D}$ perovskite network $\mathrm{M}_{2} \mathrm{X}_{9}\left(\mathrm{M}=\mathrm{Bi}^{3+} / \mathrm{Sb}^{3+}\right)$ belonging to the $\left\langle\begin{array}{lll}1 & 1 & 1\end{array}\right)$-oriented 2D family ( $q=2$ members) has been discovered. Such a network was first stabilized with $\mathrm{X}=\mathrm{Br},{ }^{20}$ while polymorph anionic clusters of two face-sharing octahedra $\left.\mathrm{Bi}_{2}\right|_{9}$ are preferentially formed with $\mathrm{X}$ $=\mathrm{I} .{ }^{16}$ However, using $\mathrm{Cs}^{+},{ }^{21} \mathrm{Rb}^{+}, 22$ or a mixture of I and $\mathrm{Cl}$ anions, ${ }^{23} 2 \mathrm{D} \mathrm{HP}$ based on $\mathrm{Sb}_{2} \mathrm{l}_{9}$ or $\mathrm{Sb}_{2} \mathrm{I}_{9-\mathrm{x}} \mathrm{Cl}_{\mathrm{x}}$ perovskite networks can be achieved and led to a PCE of $>2 \%$. In addition to non-perovskite $1 \mathrm{D} \mathrm{Bil}{ }_{4}$ having edge-sharing octahedra, ${ }^{17}$ the other well-known 1D network of the perovskite type is $\mathrm{Ml}_{5}$. This $\mathrm{Ml}_{5}$ iodobismuthate or iodoantimonate polymeric anion can exist as two isomeric chains: chains having either cis-connected

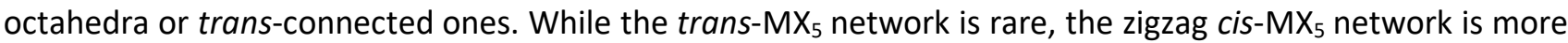
common. ${ }^{24-28}$ For instance, Ardo et al. have reported one compound based on such a cis-MX $\mathrm{X}_{5}$ network $\left(\mathrm{Bi}_{5}\right)$ for PSC applications, which led to a very low PCE $(<0.1 \%) .{ }^{26}$ The other polymorphic $1 \mathrm{D}$ chain seems to be more promising because of the trans-connectivity of the octahedra along an infinite direction, as found in $\left(\mathrm{CH}_{3} \mathrm{NH}_{3}\right) \mathrm{Pbl}_{3}$ for instance, which is not found in the 1D cis-MI $\mathrm{Ml}_{5}$ network or in the $2 \mathrm{D} \mathrm{M}_{2} \mathrm{X}_{9}(m=2 ;\langle 111\rangle$ series $)$ perovskite network. As a result of the linear $\cdots|-B i-|-B i-\mid \cdots$ chain, corresponding hybrids exhibit an intense black color as in the recent example of $\left[1,1^{\prime}-\left(1, n\right.\right.$-alkanediyl)bis(4-methylpyridinium] $\mathrm{Bil}_{5}{ }^{29}$ or in a series of compounds based on the electron acceptor methylviologen dication $\left(\mathrm{MV}^{2+}\right)$ reported by some of us, $(\mathrm{MV}) \mathrm{Ml}_{3} \mathrm{Cl}_{2}$ and $(\mathrm{MV}) \mathrm{MBr}_{3.2} \mathrm{l}_{1.8}(\mathrm{M}=\mathrm{Bi}$ or $\mathrm{Sb}),{ }^{30,31}$ or by Lang et al., (MV)Bil ${ }_{5},{ }^{32} 10$ years ago, and more recently by Gao in which (MV)Bil ${ }_{5}$ is viewed as a pseudo-3D Bi-based network. ${ }^{33}$ We aimed to explore the potential of such trans-Bil 5 materials as absorbers in PSCs. However, the very low solubility of these methylviologen-based compounds in a solvent such as DMF or DMSO precludes the formation of good quality thin films, and subsequent incorporation into solar cells. Then, our strategy was to replace the methylviologen cation $\mathrm{MV}^{2+}$ 
with the aminoviologen cation $\mathrm{AmV}^{2+}$ (4,4'-amino-bipyridinium). We anticipated that the substitution of methyl groups with amino groups would lead to isotype compounds with increased solubility in polar solvents.

Here, we report the results of our investigations of the $\mathrm{Bi}^{3+} / \mathrm{AmV}^{2+}$ system. We show that, depending on experimental conditions, three compounds can form $(\mathrm{AmV})_{3}\left(\mathrm{Bi}_{6}\right)_{2}(\mathbf{1}),(\mathrm{AmV})_{2}\left(\mathrm{Bi}_{4} \mathrm{I}_{16}\right)(2)$, and $(\mathrm{Amv}) \mathrm{Bil}_{5}(\mathbf{3})$. Their structures are based on isolated anions $\mathrm{Bil}_{6}{ }^{3-}$ and $\mathrm{Bi}_{4} \mathrm{I}_{16}{ }^{4-}$ in $\mathbf{1}$ and $\mathbf{2}$, respectively, and on the expected 1D chain of trans-connected corner-sharing octahedra in $\mathbf{3}$. These semiconductors exhibit a broad absorption band in the visible region. We use computational investigations to describe the electronic structure and the charge carrier transport properties of 1-3. In particular, we find that 3 presents an excellent effective mass for electrons because of the efficient overlap of $\mathrm{Bi}\left(6 \mathrm{p}_{\mathrm{x}}\right)$ orbitals. However, valence states are dominated by interchain interactions leading to high effective masses for holes that are detrimental for photovoltaic applications. These elements are discussed in comparison with cis-connected wires and lead-based materials. Thin film formation of 1-3 was achieved using DMSO as the solvent, allowing the realization of PSCs for $\mathbf{3}$.

\section{Experimental section}

Synthesis and Characterizations. All starting materials were of analytical grade and obtained from commercial sources (Sigma-Aldrich) without further purification: 4,4'-bipyridine (98\%), hydroxylamine-O-sulfonic acid (99\%), hydroiodic acid ( $\mathrm{HI}, \geq 57 \%$ ) with a $1.5 \%$ hypophosphorus acid stabilizer, bismuth(III) iodide (99\%), $\mathrm{KOH}$ (98\%), and K2CO3 (99\%). The 1,1'-diamino-4,4'-bipyridinium iodide $\mathrm{AmVI}_{2}$ was obtained from reaction of 4,4'bipyridine and the potassium salt of hydroxylamine-O-sulfonic acid in water (see the Supporting Information). The (AmV)Bil ${ }_{5}(3)$ crystals were obtained by evaporation of a saturated DMSO solution of $\mathrm{AmVI}_{2}$ and $\mathrm{Bil}_{3}$, taken in a 1:1 molar ratio. The crystals of two others compounds, $(\mathrm{AmV})_{3}\left(\mathrm{Bil}_{6}\right)_{2}(\mathbf{1})$ and $(\mathrm{AmV})_{2}\left(\mathrm{Bi}_{4} \mathrm{I}_{16}\right)(\mathbf{2})$, were synthesized at room temperature by the vapor diffusion method. $\mathrm{AmVI}_{2}$ and $\mathrm{Bil}_{3}$ were dissolved in $0.15 \mathrm{~mL}$ of DMSO (0.3 and $0.2 \mathrm{mmol}$, respectively, for 1 and 0.1 and $0.2 \mathrm{mmol}$, respectively, for 2) and stirred for $5 \mathrm{~min}$ to obtain saturated solutions. The vials with solutions were then placed into sealed bottles filled with $5 \mathrm{~mL}$ of antisolvents dichloromethane (DCM) and ethanol (EtOH) for $\mathbf{1}$ and 2, respectively. The single crystals suitable for single-crystal X-ray crystallography were grown along with the slow diffusion of vapor of the antisolvent into the solutions. Powder X-ray diffraction (PXRD) analysis, which was performed on a D8 Bruker diffractometer ( $\mathrm{Cu} \mathrm{K \alpha} ; \lambda=1.5418 \AA$ ) equipped with a linear Vantec super speed detector, confirmed the phase purity of compounds $\mathbf{1}$ and $\mathbf{2}$ as crystallized powders (Figures S1 and S2) and of compound $\mathbf{3}$ as a spin-coated thin film (Figure S3). For compound 3, a ${ }^{1} \mathrm{H}$ NMR study has been also carried out by dissolving several previously prepared thin films in a small quantity of deutered DMSO. The spectrum is compared to those of $\mathrm{AmVI}_{2}$ and $\mathrm{MVI}_{2}$, showing the exclusive presence of the $\mathrm{AmV}^{2+}$ viologen in $\mathbf{3}$ (Figure S4). Ultraviolet-visible measurements were taken on a Perkin-Elmer Lambada 950 spectrometer in the range of $250-800 \mathrm{~nm}$.

Single-Crystal X-ray Crystallography. X-ray diffraction data for compounds 1 and $\mathbf{2}$ were collected at 293(2) K on an Agilent SuperNova diffractometer equipped with an Atlas CCD detector and microfocus Cu Ka radiation 
$(\lambda=1.54184 \AA$ A $)$. Intensities were corrected for Lorentz polarization effects, as well as for absorption effects (multiscan method using CrysAlisPro, Agilent Technologies, version 1.171.38.46, 2015). The structures were determined using SHELXT and refined by full matrix least-squares routines against F2 using SHELXT. The hydrogen atoms were treated with a riding model. The refinements of positions and anisotropic thermal motion parameters of the non-H atoms converge to $\mathrm{R}(\mathrm{F})=0.0436$ [5022 independent reflections $\left(\mathrm{R}_{\text {int }}=\right.$ 0.0352), 265 parameters] and wR2(F2) $=0.1182$ (all data) with a goodness of fit (GOF) on F2 of 1.025 [2, $(A m V)_{3}\left(B_{i} l_{6}\right)_{2}$ and to $R(F)=0.0458$ [5300 independent reflections $\left(R_{\text {int }}=0.0448\right), 223$ parameters $]$ and wR2(F2) $=0.1175$ (all data) with a GOF on F2 of $1.017\left[\mathbf{1},(\mathrm{AmV})_{2}\left(\mathrm{Bi}_{4} \mathrm{I}_{16}\right)\right]$. A summary of crystallographic data and refinement results for both structures is provided in Tables S1 and S2. A complete list of crystallographic data, along with the atomic coordinates, anisotropic displacement parameters, and bond distances and angles for each compound, is provided in CCDC numbers 2098632 and 2098634 for $\mathbf{1}$ and 2, respectively.

Solar Cells. All solution preparation, thin film, and solar cell processing steps were carried out in a glovebox (oxygen and moisture levels of $<1 \mathrm{ppm}$ ). Unless otherwise stated, all chemicals were purchased from SigmaAldrich and used as received. A tin oxide nanoparticle dispersion (2.5 wt \% in a mixture of butanols) was purchased from Avantama. PTAA was purchased from EM Index. Prepatterned Glass ITO substrates (sheet resistance of $<7 \Omega / \mathrm{sq}$ ) were purchased from Visiontek. They were sequentially cleaned in acetone, isopropanol, and water, dried at $100^{\circ} \mathrm{C}$ overnight, and finally subjected to an ultraviolet-ozone treatment for $30 \mathrm{~min}$ immediately before use. A $30 \mathrm{~nm}$ thick $\mathrm{SnO}_{2}$ layer was then spin-coated and annealed at $200^{\circ} \mathrm{C}$ for 30 min. The (AmV)Bil 5 precursor solution was filtered through a $0.45 \mu \mathrm{m}$ PTFE filter and spin-coated. Ten seconds before the end of the program, $100 \mu \mathrm{L}$ of chlorobenzene was dropped on the film. The substrates were submitted to a $7 \mathrm{~min}$ annealing at $150^{\circ} \mathrm{C}$ to complete absorber formation. This was followed by the spincoating of the HTL layer using a $14 \mathrm{mg} / \mathrm{mL}$ PTAA solution in toluene. To increase its mobility, PTAA was doped with LiTFSI and t-BP. For $1 \mathrm{~mL}$ of a PTAA solution, the following quantities were added: $10.5 \mu \mathrm{L}$ of a LiTFSI solution (170 g/L in acetonitrile) and $5.6 \mu \mathrm{L}$ of t-BP. Finally, a $100 \mathrm{~nm}$ thick gold electrode was thermally evaporated (base pressure of $1 \times 10^{-6}$ bar) to complete device fabrication defining a $0.30 \mathrm{~cm}^{2}$ active area. The $J-V$ curves of the solar cells were acquired using a Keithley 2400 instrument under $1000 \mathrm{~W} / \mathrm{m}^{2}$ using a solar simulator from Newport Oriel. The power was calibrated with a silicon solar cell certified by the Fraunhofer ISE CalLab.

Electronic Structure Calculations. First-principles calculations are based on density functional theory (DFT) as implemented in the SIESTA package. ${ }^{34,35}$ The nonlocal van der Waals density functional of Dion et al. corrected by Cooper (C09) is used for geometry optimizations. ${ }^{36,37}$ Spin-orbit coupling is taken into account through the fully relativistic pseudopotential approach. ${ }^{38}$ To prevent conflicts between the on-site treatment and the nonlocality of C09, single-point calculations are conducted with the revPBE functional on which C09 is based. ${ }^{39}$ Core electrons are described with Troullier-Martins pseudopotentials, ${ }^{40}$ while valence wave functions are developed over a double- $\zeta$ polarized basis set of finite-range numerical pseudoatomic orbitals. ${ }^{41}$ In all cases, an energy cutoff of 150 Ry for a real-space mesh size has been used. Electronic structures are converged using 
k-point samplings of Brillouin zones of $3 \times 3 \times 3$ for $\mathbf{1}$ and $\mathbf{2}$ and $5 \times 3 \times 1$ for $\mathbf{3}$. For each compound, the experimental unit cell, well characterized by X-ray diffraction, is used. Atomic positions, however, are systematically optimized until forces are less than $0.01 \mathrm{eV} \AA^{-1}$. In the case of (AmV)Bil ${ }_{5}(3)$, the starting point was taken from the $\mathrm{X}$-ray-determined atomic positions of (MV)Bil ${ }_{5}\left(\mathrm{MV}=\mathrm{N}, \mathrm{N}^{\prime}\right.$-dimethyl-4,4'-bipyridinium), ${ }^{32}$ where methyl groups have been substituted with amino groups in the organic dications. Complementary calculations with the HSEO6 hybrid functional, ${ }^{42}$ including spin-orbit coupling, are performed with the planewave projector-augmented wave (PAW) method as implemented in the VASP code, ${ }^{43,44}$ using an energy cutoff of $400 \mathrm{eV}$ to expand the electronic wave functions. Brillouin zones are sampled using $\Gamma$-centered $2 \times 2 \times 2 \mathrm{k}$-point grids for 1 and 2 and a $4 \times 2 \times 2$ grid for 3 .

A comparison of bismuth versus lead is carried out on idealized models consisting of isolated transconnected chains of regular $\mathrm{Bil}_{6}$ and $\mathrm{Pbl}_{6}$ octahedra with I-M-I angles of $90^{\circ}$ and $\mathrm{M}-\mathrm{I}-\mathrm{M}$ angles of $180^{\circ}$. The $\mathrm{Bi}$ chain is inspired by compound 3 with $\mathrm{Bi}-\mathrm{I}$ bond distances averaged to $3.10 \AA$, while the $\mathrm{Pb}$ model is designed on the basis of the high-temperature structure of $(\mathrm{GA})_{3} \mathrm{Pbl}_{5}\left(\mathrm{GA}=\right.$ guanidinium) reported by Wilke and Casati ${ }^{45}$ with $\mathrm{Pb}-\mathrm{I}$ bond distances of $3.24 \AA$. For $\mathrm{Bi}$ and $\mathrm{Pb}$, two tetragonal cells are considered to evaluate the effect of interchain interactions. In the first, the interchain I-I distance is set to $4 \AA$, while it is enlarged to $12 \AA$ in the second.

\section{Results and Discussion}

Crystal Structures. Depending on the experimental conditions, three compounds have been obtained as pure phases in the $\mathrm{AmV}^{2+} / \mathrm{Bi}^{3+} / \mathrm{I}^{-}$system: $(\mathrm{AmV})_{3}\left(\mathrm{Bil}_{6}\right)_{2}(\mathbf{1})$ and $(\mathrm{AmV})_{2}\left(\mathrm{Bi}_{4} \mathrm{l}_{16}\right)(\mathbf{2})$ (as crystals and thin films) and (AmV)Bil ${ }_{5}$ (3) (as a thin film). Single crystals were grown by the liquid-gas diffusion method (see the Experimental Section): while nice crystals of $\mathbf{1}$ and $\mathbf{2}$ were obtained, unfortunately only thin crystals of $\mathbf{3}$ could be produced. This allowed us to determine the unit cell dimensions via single-crystal X-ray diffraction; the compound was found to be monoclinic ( $a=6.385 \AA, b=15.166 \AA, c=11.052 \AA, \beta=102.57^{\circ}$, and $V=1044 \AA^{3}$ ) and appeared to be very close to the known (MV)Bil ${ }_{5}$ compound. ${ }^{32}$ This indicates that $(\mathrm{AmV}) \mathrm{Bil}_{5}$ has a $1 \mathrm{D}$ perovskite network with chains of trans-connected corner-sharing octahedra extending along the $a$ direction. We also carried out a profile fitting of the XRD pattern of a thin film of $\mathbf{3}$, which confirmed this monoclinic unit cell (Figure S3 and the Supporting Information). Viologens are electron acceptor units. ${ }^{46}$ However, the electron acceptor character of $\mathrm{AmV}^{2+}$ may be one of the weaker among viologen molecules due to the $\mathrm{NH}_{2}$ electron donor group stabilizing pyridinium cycles. Thus, the first reduction peak of $\mathrm{AmV}^{2+}$ is at $-626 \mathrm{mV} / \mathrm{ECS}$, while that of $\mathrm{MV}^{2+}\left(\mathrm{MV}=\right.$ methylviologen) is at $-487 \mathrm{mV} / \mathrm{ECS} .{ }^{47}$ We can notice that in good agreement with redox properties, the $\mathrm{AmVI}_{2}$ viologen salt is yellow while $\mathrm{MVI}_{2}$ is red (photos and absorbance spectra in Figure S5).

$(\mathrm{AmV})_{3}\left(\mathrm{Bil}_{6}\right)_{2}(\mathbf{1})$ crystallized in the PI triclinic space group. The asymmetrical unit contains three halfmolecules leading to the centrosymmetrical V1-V3 viologen dications, two bismuth ions located on symmetry centers, and six iodide anions (Figure 1). As highlighted in the general view along the $a$ direction (Figure 1a), 
the structure is built from isolated $\mathrm{Bil}_{6}$ octahedra surrounded by viologen cations. The Bil 6 octahedra are quite regular with I-Bi-I bond angles close to $90^{\circ}\left(90 \pm 4^{\circ}\right)$ and bond distances in the range of $3.06-3.09 \AA$ [3.064(1)-3.081(1) $\AA$ for Bi1 and 3.065(1)-3.091(1) ^ for Bi2]. A first interesting feature is the different role of one of the viologens, V1, compared to the other two, $\mathrm{V} 2$ and V3 (Figure 1b). On one hand, each V2

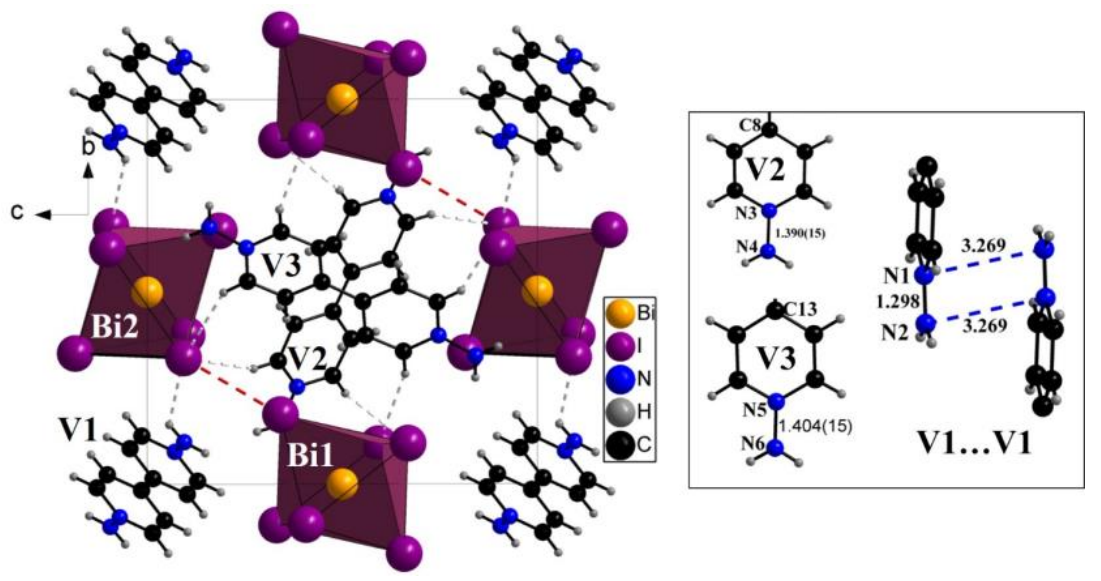

Figure 1 | Structure of $(\mathrm{AmV})_{3}\left(\mathrm{Bil}_{6}\right)_{2}$ (compound 1). (a) General view along the $a$ direction showing $H \cdots \mid(<3.00 \AA)$ and $|\cdots|(3.915 \AA)$ interactions between molecular units. The three half-independent molecules are denoted V1-V3. (b) Close-up of V1-V3 with selected bond distances and highlighted $\mathrm{V} 1 \cdots \mathrm{V} 1$ interactions through $\mathrm{N}^{+} \ldots \mathrm{NH}_{2}$ contacts. and V3 molecule makes four short $\mathrm{H} \cdots \mathrm{I}$ interactions $\left(<2.98 \AA\right.$ ) between iodides and $\mathrm{H}$ atoms connected to $\alpha \mathrm{C}$ atoms of the electrophilic $\mathrm{N}^{+}$site (range of 2.883-2.963 $\AA$ ) and the $\mathrm{N}^{+}-\mathrm{N}(\mathrm{H} 2)$ bond distance is close to $1.40 \AA$ [1.416(13) $\AA$ for V3 and 1.415(11) $\AA$ for V2]. On the other hand, the V1 molecule interacts less with iodides of Bil ${ }_{6}$ octahedra (one short $\mathrm{I} \cdots \mathrm{H}$ distance of $2.983 \AA$ involving one $\mathrm{H}$ atom of the $\mathrm{NH}_{2}$ group) but in contrast interacts with another $\mathrm{V} 1$ molecule through two $\mathrm{N}^{+} \ldots \mathrm{NH}_{2}$ interactions [3.250 $\AA$ (Figure 1b)]. A second interesting feature is the short |...| contacts of $3.915 \AA$ between two consecutive $\mathrm{Bil}_{6}$ octahedra along the $b+c$ direction, leading to infinite supramolecular chains of $\mathrm{Bil}_{6}$ octahedra through $|\cdots|$ interactions. The great number of $\mathrm{H} \cdots \mid$ contacts $(6,10$, and $8 \mathrm{H} \cdots \mid$ interactions of $<3.20 \AA$ for $\mathrm{V} 1-\mathrm{V} 3$, respectively) reveals quite strong acceptor (viologen)-donor (iodide) interactions. We must notice that one could anticipate stronger interactions between viologen and iodides in compound $\mathbf{1}$ than in $\mathbf{2}$ or $\mathbf{3}$. In fact, there is one viologen cation for four iodides (and $\left.0.66 \mathrm{Bi}^{3+}\right)$ in $(\mathrm{AmV})_{3}\left(\mathrm{Bi}_{6}\right)_{2}$, while this ratio is of one for five (and $\left.1 \mathrm{Bi}^{3+}\right)$ in $(\mathrm{AmV}) \mathrm{Bil}_{5}$ and one for eight (and $\left.2 \mathrm{Bi}^{3+}\right)$ in $(\mathrm{AmV})_{2}\left(\mathrm{Bi}_{4} \mathrm{I}_{16}\right)$. As a consequence, on average, each iodide in $\mathbf{1}$ is strongly electron-depleted as underlined by all of the $\mathrm{H} \cdots \mathrm{I}$ interactions. The strength of such acceptor-donor interactions is also revealed by the brown color of the crystals. ${ }^{46,48}$ In contrast, crystals of $(A m V)_{2}\left(\left.B i_{4}\right|_{16}\right)$ are red, which is consistent with expected weaker donor-acceptor interactions due to the unfavorable V:I ratio of 1:8.

$(\mathrm{AmV})_{2}\left(\mathrm{Bi}_{4} \mathrm{l}_{16}\right)(2)$ crystallized in the PI triclinic space group. The asymmetrical unit contains one viologen molecule, two bismuth cations, and eight iodides. The well-known centrosymmetrical $\mathrm{Bi}_{4} \mathrm{l}_{16}$ cluster built up from four edge-sharing $\mathrm{Bil}_{6}$ octahedra is formed (Figure 2). As expected, the Bi-I bond distances involving terminal iodides [three $\mathrm{d}(\mathrm{Bi}-\mathrm{I})<2.97 \AA$ for $\mathrm{Bi} 1$, and two $\mathrm{d}(\mathrm{Bi}-\mathrm{I})<2.92 \AA$ for $\mathrm{Bi2}$ ] are shorter than those involving shared iodides [three $\mathrm{d}(\mathrm{Bi}-\mathrm{I})>3.24 \AA \AA$ for $\mathrm{Bi} 1$, and four $\mathrm{d}(\mathrm{Bi}-\mathrm{I})>3.06 \AA \AA$ for $\mathrm{Bi} 2$ ], the overall bond distance ranges being 2.884-3.403 and 2.902-3.354 ̊̊ for Bi1 and Bi2, respectively. In sheets roughly parallel to the $b-c$ plane, the structural arrangement is typical of an ionic salt, with $\left.\mathrm{Bi}_{4}\right|_{16}{ }^{4-}$ anions surrounded by four dimers of viologen cations, and vice versa (Figure 2). As in compound 1, similar weak interactions are present, 


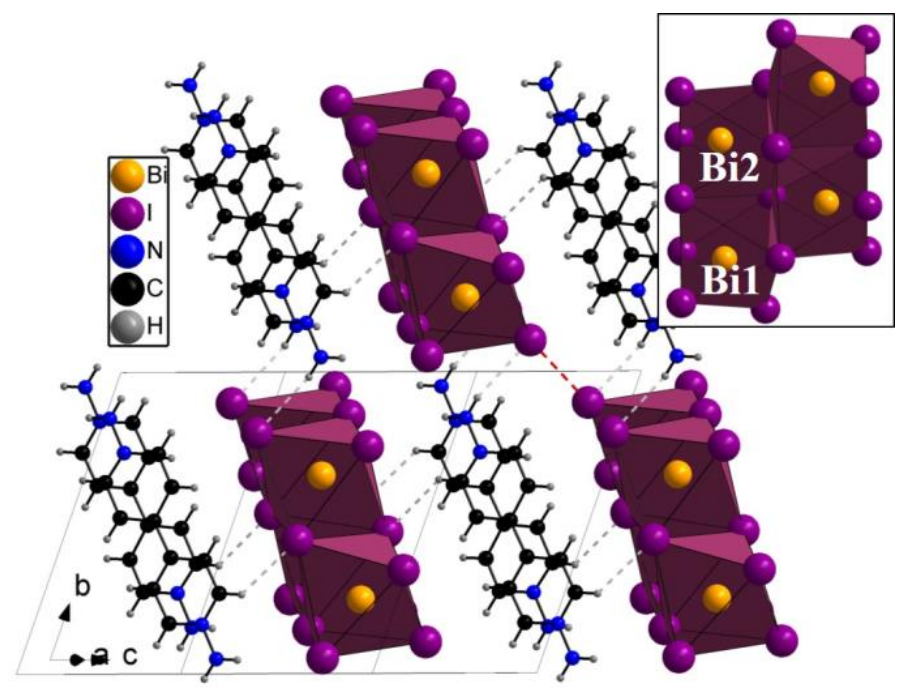

Figure 2 | Structure of $(\mathrm{AmV})_{2}\left(\mathrm{Bi}_{4} \mathrm{l}_{16}\right)$ (compound 2). General view of the structure showing $\mathrm{H} \cdots \mid(<3.04 \AA)$ and $|\cdots|(3.776$ $\AA$ ) interactions between viologen cations and $\mathrm{Bi}_{4} \mathrm{l}_{16}{ }^{4-}$ anions. The inset shows the iodobismuthate cluster of four edgesharing $\mathrm{Bil}_{6}$ octahedra.

such as the short $3.776 \AA|\cdots|$ contact between terminal iodides of two adjacent clusters. For $\mathrm{H} \cdots$ I interactions revealing acceptor-donor interactions, one may notice a significantly lower number in compound 2 (six $<3.20 \AA$ interactions for each molecule) than in compound $\mathbf{1}(6,8$, and $10<3.20 \AA$ interactions for the three independent molecules). In 2, one $\mathrm{H} \cdots$ I interaction involves $\mathrm{H}$ atoms of the $\mathrm{NH}_{2}$ group $(\mathrm{d}=2.851 \AA$ ) and two involve $\mathrm{H}$ atoms bond to $\alpha \mathrm{C}$ atoms of the $\mathrm{N}+$ site $(d=3.018 \AA$, and $d=3.033 \AA$ ).

Thin films of the three compounds have been prepared successfully by spin-coating (S.I.), as shown by PXRD (Figures S1-S3). The absorption spectra are provided in Figure 3a, showing that the absorption abilities in the visible region decrease in the following order: $\mathbf{3}>\mathbf{1}>\mathbf{2}$. Corresponding Tauc plots have been drawn (Figure $3 b$ for $\mathbf{3}$ and Figure S6 for $\mathbf{1}$ and 2), leading to an optical bandgap of $1.54 \mathrm{eV}$ for 3.
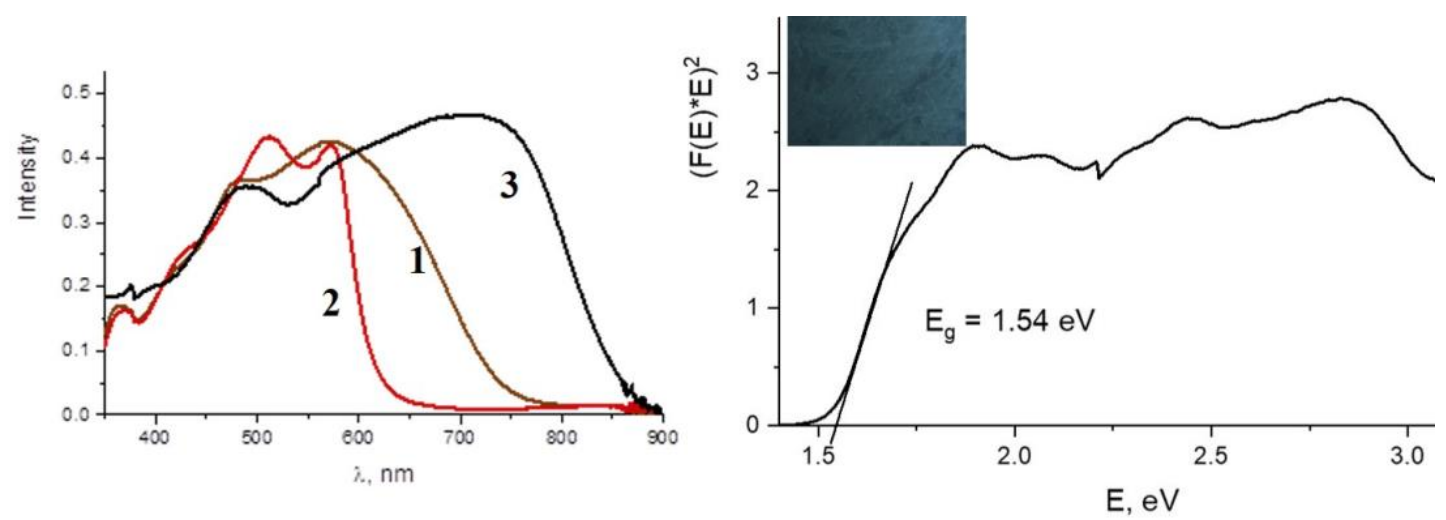

Figure 3 | (a) Absorption spectra of compounds 1-3. (b) Tauc plot for compound 3 (direct bandgap).

Theory and Electronic Structure Calculations. Insights into the electronic structure of compounds 1-3 are provided by first-principles calculations based on DFT. Hybrid halide perovskites and similar structures have been extensively studied in the recent past. Typically, the top valence bands are formed mostly by contributions from $n p$ orbitals of the halide (e.g., iodine) and smaller ones from the $n$ s orbitals of the metal (e.g., bismuth), the bottom conduction bands consist mostly of $n p$ orbitals of the metals, and the organic cation contributions are found away from the band edges. The band structures and projected densities of states (pDOS) of 1-3 are provided in Figure 4 (main features summarized in Table S3). First, one can notice the 
unusual large involvement of organic states near the band edges for all structures. Indeed, if the valence band maximums (VBMs) are built by the usual combination of $\mathrm{I}(5 \mathrm{p})$ and $\mathrm{Bi}(6 \mathrm{~s})$ orbitals, the conduction band minimums (CBMs) of $\mathbf{1}$ and $\mathbf{2}$ are due to AmV cations, while those states appear near the CBM ( 0.2 eV) for 3. The ordering between organic and inorganic states computed for 1 and $\mathbf{2}$ could be caused by the well-known failure of plain DFT to describe the band edges of different classes of materials with the same level of accuracy. We further checked the possible intercalation of organic states between the inorganic ones using hybrid DFT calculations, with the HSE06 exchange-correlation functional that is likely to correct this shortcoming of plain DFT (Figure S8). Still, the organic states contribute to the conduction band. As HSEO6 is known to afford a better estimation of fundamental electronic bandgaps, we will use the latter level of theory to discuss bandgaps.

1 displays a direct bandgap at $\mathrm{V}\left(E_{G}=0.96 \mathrm{eV}\right)$ in its band structure (Figure 4a). However, when considering only the bands arising from the inorganic lattice, we find the corresponding bandgap becomes indirect at $\mathrm{V} \rightarrow \mathrm{U}$ with an $E_{G}$ of $2.15 \mathrm{eV}$. The absorption spectra of 1 are described through the band-to-band computation of the absorption coefficient at the hybrid DFT level of theory (Figure S8). It shows a first peak at $2.15 \mathrm{eV}$, which corresponds to the position of the $\mathrm{Bi}-\mathrm{I}$ states. However, this peak is preceded by a slowly growing signal. To attribute this feature of the spectrum, similar optical absorption calculations have been performed on the inorganic skeleton of $\mathbf{1}$, while the organic cations are emulated by a background charge (dotted lines in Figure S8b). The later shows a weaker response between $\sim 1.25$ and $\sim 2.15 \mathrm{eV}$, indicating that this part of the spectrum is indeed a signature from the $A m V$ organic cations. It is worth noting that this energy window is slightly higher than the position of the lowest unoccupied molecular orbitals (LUMOs) of AmV cations with respect to the VBM defined by $\mathrm{Bi}-\mathrm{I}$ states. However, it could match the difference in energy between the LUMO and the highest occupied molecular orbitals (HOMOs) of AmV cations. It also fits the optical spectrum of $(\mathrm{AmV}) \mathrm{I}_{2}$ (Figure S5). We cannot reach a conclusion at this point about the existence of a photoinduced charge transfer from the inorganic Bil ${ }_{6}$ octahedra to the AmV cations. Remarkably, the computed effective masses for 1 , i.e., $m_{h}=-0.280 m_{0}$ and $m_{e}=-0.240 m_{0}$ for the hole and electron, respectively (Table S3), are much lower than could be expected from a structure with isolated Bil $_{6}$ octahedra. This is a direct consequence of the short contacts found between octahedra.

$\mathbf{2}$ presents many of the features described for $\mathbf{1}$ (Figure 4b), with a CBM formed by AmV states leading to an indirect bandgap at $Z \rightarrow X$ of $1.65 \mathrm{eV}$ (Figure S7 and Table S3), while the inorganic bandgap is direct at $Z$ with an $E_{G}$ of $2.02 \mathrm{eV}$, i.e., slightly smaller than that of $\mathbf{1}$, an effect of the reduced quantum confinement resulting from having groups of four octahedra instead of one. As opposed to 1, the optical threshold computed for $\mathbf{2}$ coincides with the presence of inorganic states near $2 \mathrm{eV}$ and the organic cations do not lead to intense direct absorption below the inorganic optical gap (Figure S8). Comparable although slightly larger effective masses are found for $\mathbf{2}$ despite smaller contacts between iodides (Table S3).

A very different electronic structure is obtained for $\mathbf{3}$ as a result of the trans-Bil ${ }_{5}$ network (Figure $4 c$ ), with a direct bandgap at $\mathrm{Y}$ of $1.00 \mathrm{eV}$ (Figure $\mathrm{S} 8$ and Table S3), with both VBM and CBM due to inorganic states 


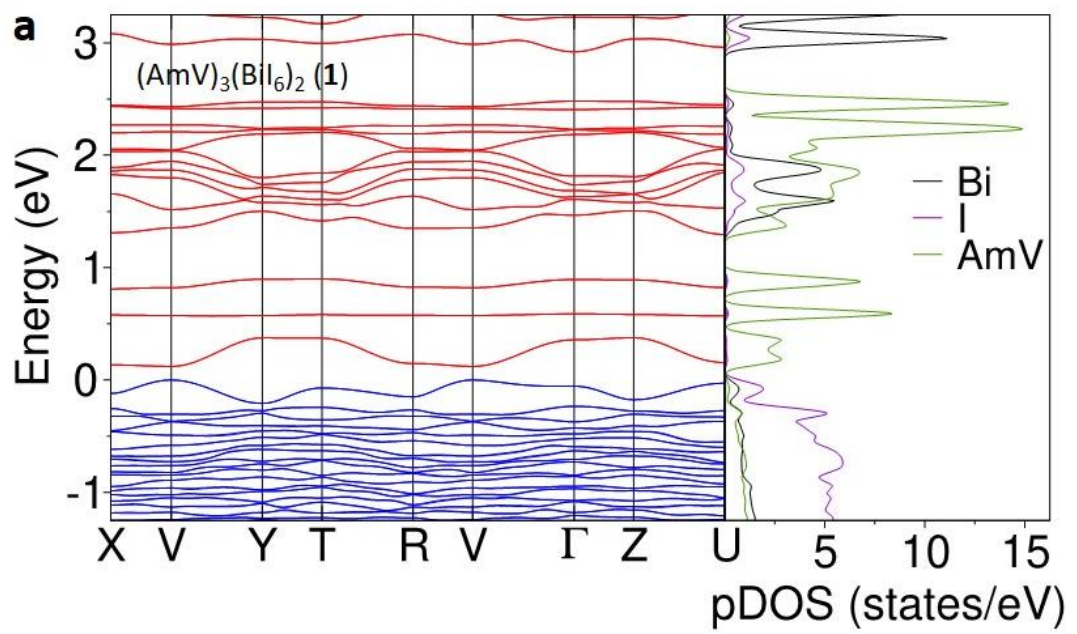

(Figure $4 c$ and Figure S8). It leads to a computed optical gap significantly lower than that of $\mathbf{1}$ and $\mathbf{2}$ (Table S3), suggesting that $\mathbf{3}$ may be particularly appealing for PV applications. However, use in PV devices also requires good transport properties from the materials to extract the generated charges. The optimized

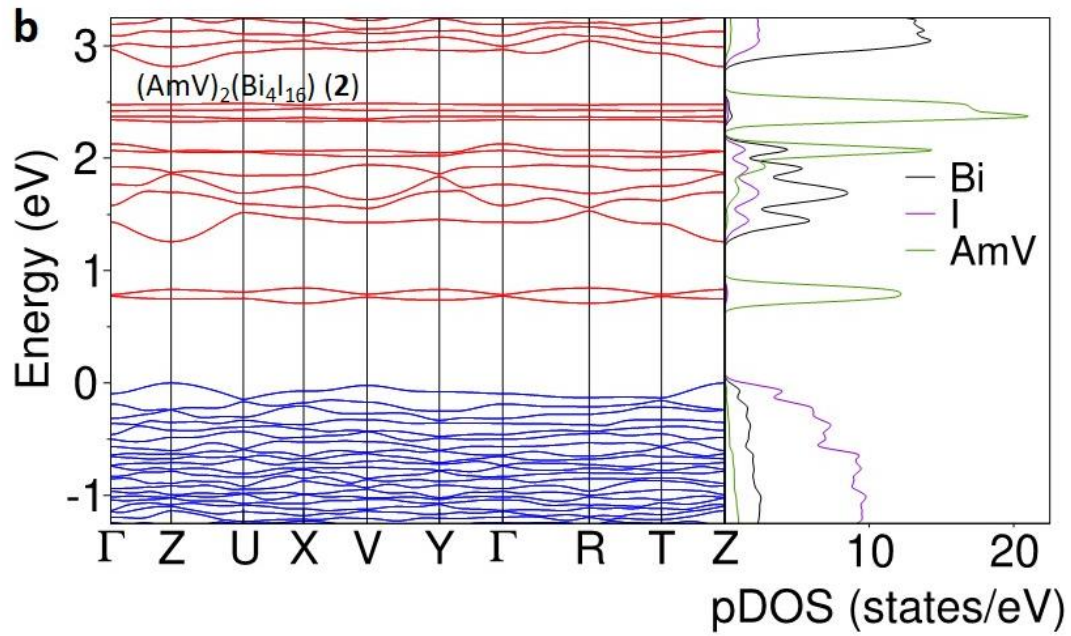

structure of $\mathbf{3}$ (see the Experimental Section for details) consists of transconnected corner-sharing $\mathrm{Bil}_{6}$ octahedra along the $a$ direction. The latter is therefore expected to be the preferential direction for electronic transport in this anisotropic material. It is indeed the case for the electrons, thanks to a CBM that presents an important dispersion in the direction

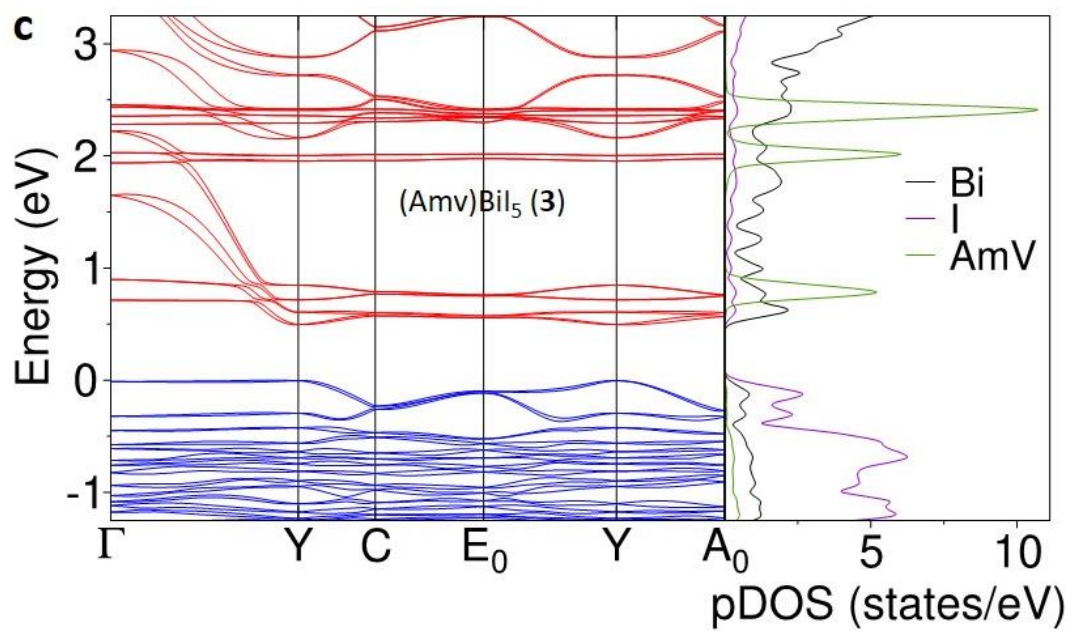

Figure 4 | Band structures (left) and projected densities of states (pDOS, right) computed with the revPBE functional for (a) $(\mathrm{AmV})_{3}\left(\mathrm{Bi} \mathrm{I}_{6}\right)_{2}(1)$, (b) $(\mathrm{AmV})_{2}\left(\mathrm{Bi}_{4} \mathrm{l}_{16}\right)(2)$, and (c) the trans-connected network (AmV)Bil ${ }_{5}(3)$. The Brillouin zones of the PI and P21 groups are shown in Figure S7. The origin of the energy scale is taken as the top of the valence band. of reciprocal space corresponding to the chain (Figure 4c) and a very low effective mass for the electron $\left[0.060 m_{0}\right.$ (Table S3)]. However, the hole effective mass becomes very large in that direction $\left(-2.800 m_{0}\right), 1$ order of magnitude larger than that obtained for $\mathbf{1}$, leading to poor hole transport properties for $\mathbf{3}$ along the chain. This surprising result can be understood from the wave function modulus at the VBM and CBM (Figure 5). Indeed, if the CBM displays large contributions from the $\mathrm{Bi}\left(6 \mathrm{p}_{x}\right)$ orbital and a strong coupling between $\mathrm{Bi}$ atoms in the chain direction, the VBM shows no contribution in that direction, while the interchain interactions are favored. As a result, the hole effective mass perpendicular to the wire direction is much better $\left(-0.150 m_{0}\right)$, while the electron effective mass, although greater than along the $a$ direction, remains moderate $\left(0.340 m_{0}\right)$. 


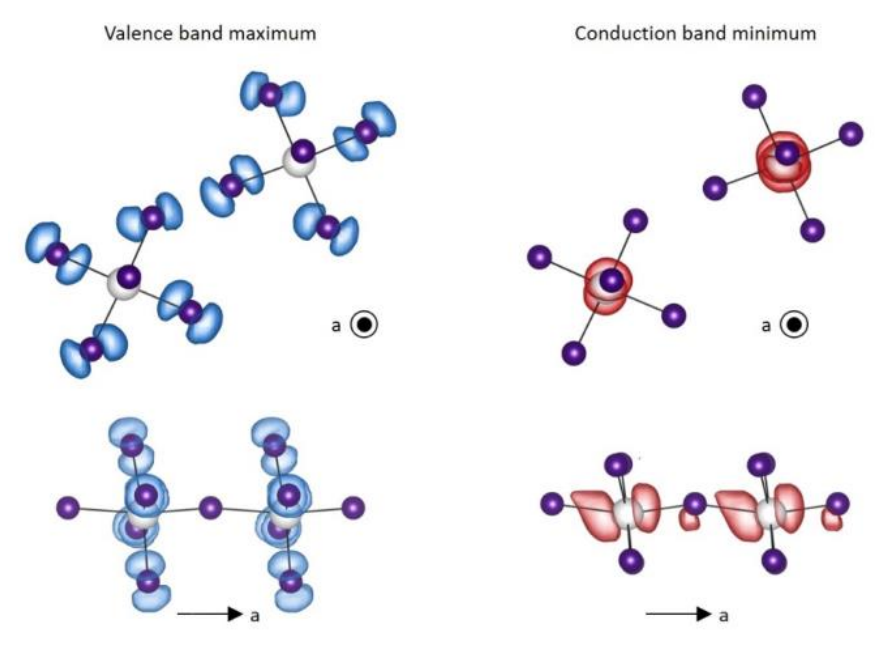

Figure 5 | Band edge states of the trans-connected Bil 5 network in 3. Moduli of the wave functions taken at the valence band maximum (left, blue isosurface) and conduction band minimum (right, red isosurface). The valence state shows no coupling along the wire direction, leading to a high effective mass for holes along the transconnected chain axis $a$. By contrast, the strong coupling between $\mathrm{Bi} 6 \mathrm{p}_{x}$ orbitals in the same direction at the conduction band minimum suggests sizable electron transport properties.

The poor hole transporting properties of $\mathbf{3}$ are surprising. Indeed, strings of corner-sharing metal halide octahedra are usually perceived as the optimal configuration for efficient transport of electrons and holes. As an example, it is the case for lead-based halide perovskites, in the three directions for 3D materials or perpendicular to the stacking axis for 2D structures. Here, the proximity of neighboring chains promotes a VBM with stronger electronic coupling between the trans-Bil 5 wires, which is less favorable for hole transport properties. To further explore the effect of interchain interaction on the electronic and transport properties, we designed trans-connected $\mathrm{MI}_{5}$ chain model systems (Figure $6 \mathrm{a}, \mathrm{c}$ and Figure $\mathrm{S} 10 \mathrm{a}, \mathrm{b}$ ). It is noteworthy that interchain distances and in turn interactions could be tuned by cation engineering. For close-packed trans-Bil ${ }_{5}$ chains (Figure 6a), we recover the behaviour of 3, with a VBM made of iodide dangling bonds that are unfavorable to hole transport along the chain. When moving to isolated chains (Figure $6 c$ ), this valence state is lower in energy and the VBM now shows a sizable weight on the iodine atoms involved in the corner-sharing pattern. However, the hybridization between $\mathrm{I}\left(5 \mathrm{p}_{x}\right)$ and $\mathrm{Bi}(6 \mathrm{~s})$ orbitals, which would lead to a strongly dispersive band and a low hole effective mass, does not rise to the top valence band (Figure S10). Instead, the VBM is composed mainly of bridging iodine $5 p$ orbitals orthogonal to the chain direction, still leading to a sizable hole effective mass $\left(-0.600 m_{0}\right)$. Thus, enhancing the interchain distance is not sufficient for improving hole charge transport properties in trans-Bil 5 wires. The very same investigation can be carried out on trans$\mathrm{Pbl}_{5}$ networks (Figure $6 \mathrm{c}$ and Figure S11). In the first case, with short interchain distances, we retrieve the same picture as with $\mathrm{Bi}$, i.e., a $\mathrm{CBM}$ built on $\mathrm{Pb}\left(6 \mathrm{p}_{x}\right) / \mathrm{I}(5 \mathrm{~s})$ orbitals with a low electron effective mass (Figure $6 e)$, while the VBM is governed by interchain interactions, leading to a high hole effective mass. However, by 
contrast with $\mathrm{Bi}, \mathrm{Pbl}_{5}$ isolated chains present a $\mathrm{VBM}$ with the desired $\mathrm{I}\left(5 \mathrm{p}_{x}\right) / \mathrm{Pb}(6 \mathrm{~s})$ mixing driving a hole effective mass almost as small as the electron one (Figure 6h). The difference in behavior between $\mathrm{Pb}$ and $\mathrm{Bi}$ can be traced back to the smaller 6s/6p splitting observed in $\mathrm{Pb}$ (Figure S11) that destabilizes the antibonding $\mathrm{I}\left(5 p_{x}\right) / \mathrm{Pb}(6 \mathrm{~s})$ combination over the mixing of $\mathrm{I}(5 \mathrm{p})$ orbitals. Hence, cation engineering that aims to achieve greater spacing between trans- $\mathrm{Pbl}_{5}$ chains could produce $1 \mathrm{D} \mathrm{Pbl}_{5}$ wires with appealing optoelectronic properties.
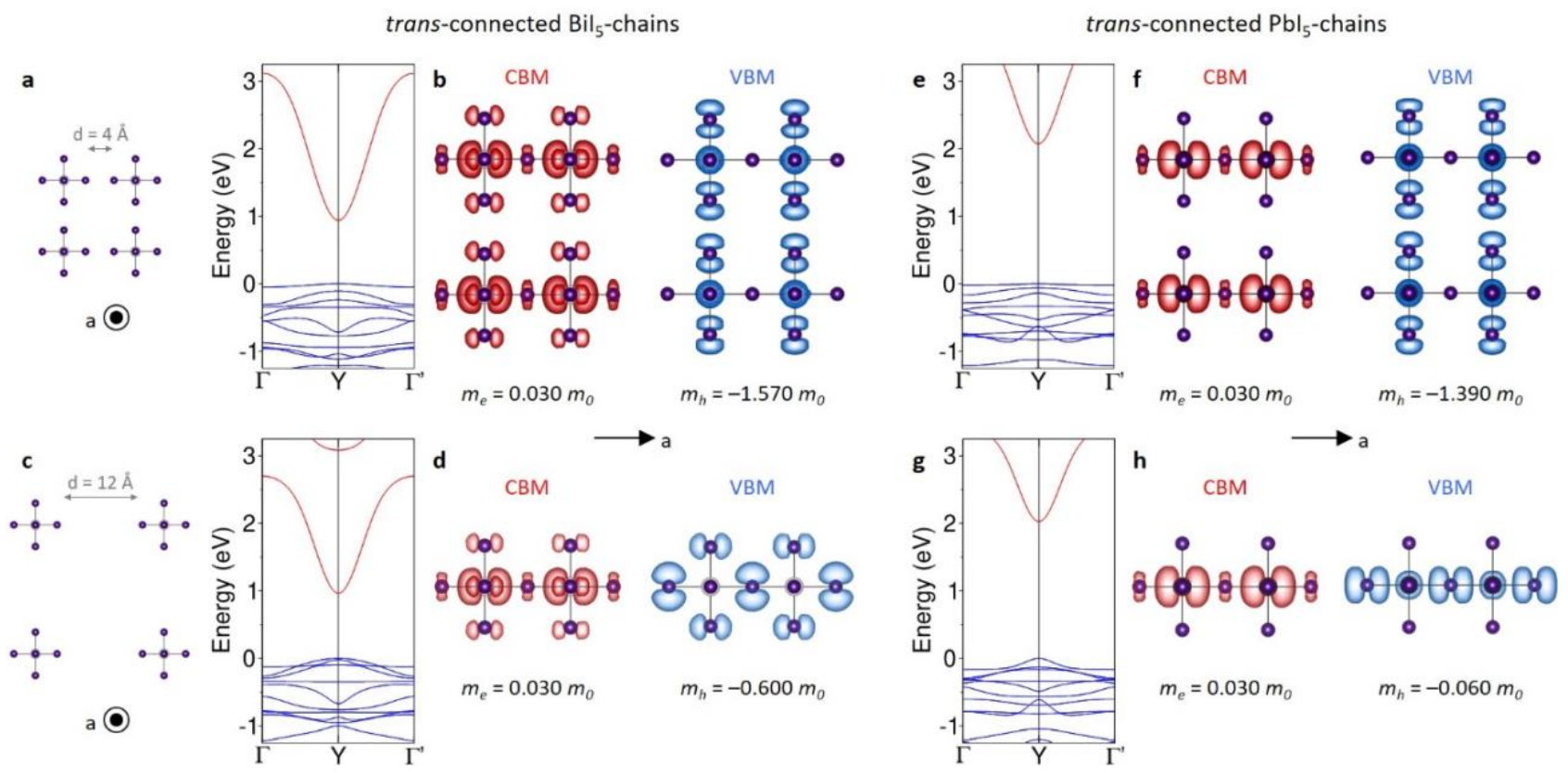

Figure 6 | Electronic properties of trans-connected $\mathrm{Ml}_{5}$ model structures $(\mathrm{M}=\mathrm{Bi}$ or $\mathrm{Pb})$. trans-connected Bil ${ }_{5}$ (left) and $\mathrm{Pbl}_{5}$ (right) wires with short ( $4 \AA$, top) and long $(12 \AA$, bottom) interchain distances. (a and e) Band structures of model trans-connected $\mathrm{Bil}_{5}$ and $\mathrm{Pbl}_{5}$ chains with short interchain distances. (b and f) Corresponding wave function moduli taken at the CBM (red) and VBM (blue). (c and g) Band structures of model chains with long interchain distances. ( $\mathrm{d}$ and $\mathrm{h}$ ) Corresponding wave function moduli taken at the CBM and VBM. Even without close packing, trans-connected Bil $_{5}$ chain valence states are dominated by a low dispersive state with a high hole effective mass in the chain direction. On the contrary, trans-connected $\mathrm{Pbl}_{5}$ wires, if separated enough, present a VBM built on $\mathrm{Pb}(6 \mathrm{~s}) / \mathrm{I}(5 \mathrm{p})$ combination, optimal for charge transport.

Solar Cells. To evaluate the performance of our newly synthesized trans-connected Bil 5 perovskite wires, we incorporate thin films of $\mathbf{3}$ into solar cell devices. Thin films were prepared from a DMSO solution by spin coating on Glass ITO substrates previously coated with a $30 \mathrm{~nm}$ thick $\mathrm{SnO}_{2}$ layer. From mechanical profilometry measurements, the film roughness was typically very low when an antisolvent quenching step was applied [Ra 6-7 nm (Figure S12)], indicating good film forming properties under such conditions. Conversely, rough films exhibiting large pinholes and hence poor substrate coverage were obtained without this quenching step. The XRD patterns of the substrate $\left(\mathrm{ITO} / \mathrm{SnO}_{2}\right)$ and thin films of $\mathbf{3}$ are reported in Figure 7a. Two strong lines assigned to $\left(\begin{array}{lll}1 & 0 & 0\end{array}\right)$ and $\left(\begin{array}{lll}2 & 0 & 0\end{array}\right)$ planes are observed, indicating a preferential orientation of $\left(\begin{array}{ll}0 & 0\end{array}\right)$ planes parallel to the substrate. This also means that the trans-connected corner-sharing octahedral chains extending along the $a$ parameter are perpendicular to the substrate. As illustrated in Figure 3a, thin films of 3 present a relatively good absorbance in the visible range. From the Tauc plot (Figure 3b) made 
assuming a direct transition, the bandgap was determined to be $\sim 1.54 \mathrm{eV}$, yet no significant photoluminescence emission was recorded on the thin films for excitation ranging from 400 to $780 \mathrm{~nm}$. The potential of $\mathbf{3}$ as an absorber in solar cells was then evaluated. To this end, so-called NIP type devices were processed with a Glass ITO/SnO $2 /(\mathrm{AmV}) \mathrm{Bil}_{5} / \mathrm{PTAA} / \mathrm{Au}$ architecture. The $J-V$ curve of the best-performing device is displayed in Figure 7b. Even though device efficiency remained low $(<0.1 \%)$, a significant open-circuit voltage close to $500 \mathrm{mV}$ was recorded, evidencing the presence of a PV effect. From the $J-V$ curve presented, it is clear that the device efficiency is especially limited by a very low current output, typically $<0.1 \mathrm{~mA} / \mathrm{cm}^{2}$. With a $1.54 \mathrm{eV}$ bandgap, a current density in the range of $20 \mathrm{~mA} / \mathrm{cm}^{2}$ can be achieved with high-performance absorbers (such as lead halide perovskites, for instance). As the absorption properties of $\mathbf{3}$ are relatively good, they cannot explain this result. The current limitation could then stem from limited hole transport properties as predicted using DFT calculations, particularly because the trans-Bil ${ }_{5}$ perovskite wires offer high hole effective masses and show lower ones in the directions perpendicular to the substrate.
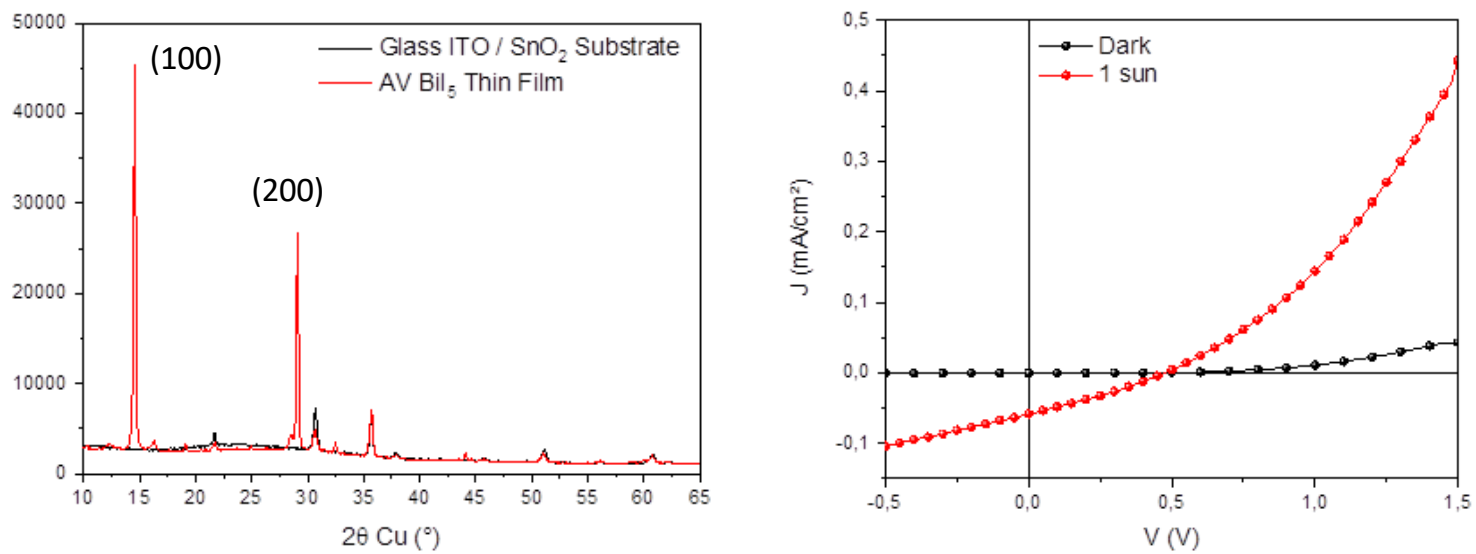

Figure 7 | (a) XRD pattern of a thin film of 3 showing a preferential orientation of (h 00 ) planes parallel to the substrate. (b) J-V curves in the dark and with $1000 \mathrm{~W} / \mathrm{m} 2$ of the highest-performance device made with 3.

\section{Conclusion}

The substitution of a methyl group of methylviologen $\left(\mathrm{MV}^{2+}\right)$ with an amino group, giving aminoviologen $\left(\mathrm{AmV}^{2+}\right)$, was shown to improve the solubility in a polar solvent of the corresponding iodobismuthate hybrid materials. In turn, three organic-inorganic hybrid materials, $(\mathrm{AmV})_{3}\left(\mathrm{Bil}_{6}\right)_{2}(\mathbf{1}),(\mathrm{AmV})_{2}\left(\mathrm{Bi}_{4} \mathrm{I}_{16}\right)(\mathbf{2})$, and $(\mathrm{AmV}) \mathrm{Bil}_{5}$ (3), have been obtained as thin films through a spin-coating process as well as crystallized powders. The crystal structures are based on isolated $\mathrm{Bil}_{6}{ }^{3-}$ and $\left.\mathrm{Bi}_{4}\right|_{16}{ }^{4-}$ anion clusters in $\mathbf{1}$ and $\mathbf{2}$, respectively, and on $1 \mathrm{D}$ transconnected corner-sharing octahedral chains in 3. (AmV)Bil ${ }_{5}$ exhibits a broad absorption band in the whole visible region, and upon incorporation into a solar cell device, the presence of a PV effect is demonstrated with a significant open-circuit voltage close to $500 \mathrm{mV}$. For these 1D trans-connected Bils wires, DFT calculations predict significantly lower hole effective masses compared to those of electrons. Interestingly, due to halogen-halogen interactions, hole transport is likely to be better between the $\mathrm{Bil}_{5}$ chains. The poor hole transport properties are likely to contribute to the modest device efficiency. Further rationalization of 
the effect of the corner-sharing mode of the chain on its electronic and transport properties is obtained by comparing its electronic structure to that of the 1D zigzag cis-connected structure of (DMES)Bil5. Whereas the $\mathrm{Bi}-\mathrm{Bi}$ electronic coupling along the chain direction is reduced in the CBM of (DMES)Bils, it is increased in the VBM, increasing and decreasing the corresponding effective masses, respectively. trans-connected $\mathrm{MI}_{5}(\mathrm{M}=$ $\mathrm{Bi}$ or $\mathrm{Pb}$ ) model structures are further explored in the quest to offer design rules for cation engineering. It is shown that the desired hybridization in the VBM of I $5 p$ orbitals and $M 6$ s orbitals is met only for $\mathrm{M}=\mathrm{Pb}$ when the interchain distance is large enough. Meanwhile, the nature of the CBM is hardly affected by the substitution or the interchain distance. Hence, whereas there is little hope of reaching good hole transport properties in any trans-connected $\mathrm{Bil}_{5}$ wire, they can be improved with a cis-connected mode but at the expense of the mobility of electrons. Unfortunately, once more, appealing optoelectronic properties are predicted for lead-based materials, here with specific cation engineering to ensure a sufficiently large interchain distance between trans-connected corner-sharing $\mathrm{Pbl}_{5}$ wires.

\section{Supporting Information}

The Supporting Information presents supplementary experimental characterization results, data analysis, DFT results, and additional figures and tables.

\section{Accession Codes}

CCDC 2098632 and 2098634 contain the supplementary crystallographic data for this paper. These data can be obtained free of charge via www.ccdc.cam.ac.uk/data request/cif, or by emailing data request@ccdc.cam.ac.uk, or by contacting The Cambridge Crystallographic Data Centre, 12 Union Road, Cambridge CB2 1EZ, UK; fax: +44 1223336033.

\section{Acknowledgments}

At ISCR and MOLTECH-Anjou, the work was mainly supported by the Agence Nationale pour la Recherche (MORELESS project). For DFT calculations, this work was granted access to the HPC resources of TGCC/CINES/IDRIS under Allocation 2020-A0090907682 made by GENCI. ISCR has benefited from the support of European Union's Horizon 2020 research and innovation Programme under the grant agreement no. 862656. The information and views set out in the abstracts and presentations are those of the authors and do not necessarily reflect the official opinion of the European Union. Neither the European Union institutions and bodies nor any person acting on their behalf may be held responsible for the use which may be made of the information contained herein. 


\section{References}

[1] Brenner, T. M.; Egger, D. A.; Kronik, L.; Hodes, G.; Cahen, D. Hybrid organic-inorganic perovskites: low-cost semiconductors with intriguing charge-transport properties. Nat. Rev. Mater. 2016, 1, 15007-15022.

[2] Song, Z.; McElvany, C. L.; Phillips, A. B.; Celik, I.; Krantz, P. W.; Watthage, S. C.; Liyanage, G. K.; Apul, D.; Heben, M. A technoeconomic analysis of perovskite solar module manufacturing with low-cost materials and techniques. Energy Environ. Sci. 2017, 10, 1297-1305.

[3] National Renewable Energy Laboratory. https://www.nrel.gov/pv/assets/pdfs/best-research-cellefficiencies.20200104.pdf (accessed 2021-07-16).

[4] Shao, S.; Liu, J.; Portale, G.; Fang, H. H.; Blake, G. R.; ten Brink, G. H.; Koster, L. J. A.; Loi, M. A. Highly reproducible Sn-based hybrid perovskite solar cells with 9\% efficiency. Adv. Energy Mater. 2018, 8, 1702019.

[5] Babayigit, A.; Duy Thanh, D.; Ethirajan, A.; Manca, J.; Muller, M.; Boyen, H.-G.; Conings, B. Assessing the toxicity of $\mathrm{Pb}$ - and $\mathrm{Sn}$-based perovskite solar cells in model organism Danio rerio. Sci. Rep. 2016, 6, 18721.

[6] Shi, Z.; Guo, J.; Chen, Y.; Li, Q.; Pan, Y.; Zhang, H.; Xia, Y.; Huang, W. Lead-Free Organic-Inorganic Hybrid Perovskites for Photovoltaic Applications: Recent Advances and Perspectives. Adv. Mater. 2017, $29,1605005$.

[7] Xiao, Z.; Song, Z.; Yan, Y. From Lead Halide Perovskites to Lead-Free Metal Halide Perovskites and Perovskite Derivatives. Adv. Mater. 2019, 31, 1803792.

[8] Chatterjee, S.; Pal, A. J. Influence of metal substitution on hybrid halide perovskites: towards lead-free perovskite solar cells. J. Mater. Chem. A 2018, 6, 3793-3823.

[9] Yang, X.; Chen, Y.; Liu, P.; Xiang, H.; Wang, W.; Ran, R.; Zhou, W.; Shao, Z. Simultaneous Power Conversion Efficiency and Stability Enhancement of $\mathrm{Cs}_{2} \mathrm{AgBiBr}_{6}$ Lead-Free Inorganic Perovskite Solar Cell through Adopting a Multifunctional Dye Interlayer. Adv. Funct. Mater. 2020, 30, 2001557.

[10] Slavney, A. H.; Hu, T.; Lindenberg, A. M.; Karunadasa, H. I. A Bismuth-Halide Double Perovskite with Long Carrier Recombination Lifetime for Photovoltaic Applications. J. Am. Chem. Soc. 2016, 138, 2138-2141.

[11] Slavney, A. H.; Leppert, L.; Saldivar-Valdes, A.; Bartesaghi, D.; Savenije, T. J.; Neaton, J. B.; Karunadasa, H. I. SmallBand-Gap Halide Double Perovskites. Angew. Chem. Int. Ed. 2018, 57, 12765-12770.

[12] Mercier, N.; Louvain, N.; Bi, W. Structural Diversity and Retro-Crystal Engineering Analysis of lodometalate hybrids. CrystEngComm 2009, 11, 720-734.

[13] Kamminga, M. E.; Stroppa, A.; Picozzi, S.; Chislov, M.; Zvereva, I. A.; Baas, J.; Meetsma, A.; Blake, G. R.; Palstra, T. T. M. Polar Nature of $\left(\mathrm{CH}_{3} \mathrm{NH}_{3}\right)_{3} \mathrm{Bi}_{2}$ l $_{9}$ Perovskite-Like Hybrids. Inorg. Chem. 2017, 56, 33-41.

[14] Szklarz, P.; Gạgor, A.; Jakubas, R.; Zieliński, P.; Piecha-Bisiorek, A.; Cichos, J.; Karbowiak, M.; Bator, G.; Ciżman,

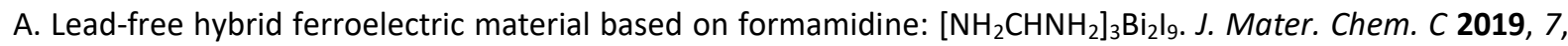
3003-3014.

[15] Bi, W.; Louvain, N.; Mercier, N.; Luc, J.; Sahraoui, B. Type structure, which is composed of organic diammonium, triiodide and hexaiodobismuthate, varies according to different structures of incorporated cations. CrystEngComm 2007, 9, 298-303.

[16] Park, B.-W.; Philippe, B.; Zhang, X.; Rensmo, H.; Boschloo, G.; Johansson, E. M. J. Bismuth Based Hybrid Perovskites $\mathrm{A}_{3} \mathrm{Bi}_{2} \mathrm{l}_{9}$ (A: Methylammonium or Cesium) for Solar Cell Application. Adv. Mater. 2015, 27, 6806-6813.

[17] Li, T.; Wang, Q.; Nichol, G. S.; Morrison, C. A.; Han, H.; Hu, Y.; Robertson, N. Extending lead-free hybrid photovoltaic materials to new structures: thiazolium, aminothiazolium and imidazolium iodobismuthates. Dalton Trans. 2018, 47, 7050-7058.

[18] Katan, C.; Mercier, N.; Even, J. Quantum and Dielectric Confinement Effects in Lower-Dimensional Hybrid Perovskite Semiconductors. Chem. Rev. 2019, 119, 3140-3192.

[19] Mitzi, D. B. Organic-Inorganic Perovskites Containing Trivalent Metal Halide Layers: The Templating Influence of the Organic Cation Layer. Inorg. Chem. 2000, 39, 6107-6113.

[20] Bass, K. K.; Estergreen, L.; Savory, C. N.; Buckeridge, J.; Scanlon, D. O.; Djurovich, P. I.; Bradforth, S. E.; Thompson, M. E.; Melot, B. C. Vibronic Structure in Room Temperature Photoluminescence of the Halide Perovskite $\mathrm{Cs}_{3} \mathrm{Bi}_{2} \mathrm{Br}_{9}$. Inorg. Chem. 2017, 56, 42-45.

[21] Saparov, B.; Hong, F.; Sun, J.-P.; Duan, H.-S.; Meng, W.; Cameron, S.; Hill, I. G.; Yan, Y.; Mitzi, D. B. Thin-Film Preparation and Characterization of $\mathrm{Cs}_{3} \mathrm{Sb}_{2} \mathrm{I}_{9}$ : A Lead-Free Layered Perovskite Semiconductor. Chem. Mater. 2015, 27, 5622-5632.

[22] Harikesh, P. C.; Mulmudi, H. K.; Ghosh, B.; Goh, T. W.; Teng, Y. T.; Thirumal, K.; Lockrey, M.; Weber, K.; Koh, T. M.; Li, S.; Mhaisalkar, S.; Mathews, N. Rb as an Alternative Cation for Templating Inorganic Lead-Free Perovskites for Solution Processed Photovoltaics. Chem. Mater. 2016, 28, 7496-7504.

[23] Jiang, F.; Yang, D.; Jiang, Y.; Liu, T.; Zhao, X.; Ming, Y.; Luo, B.; Qin, J.; Fan, J.; Han, H.; Zhang, L.; Zhou, Y. ChlorineIncorporation-Induced Formation of the Layered Phase for Antimony-Based Lead-Free Perovskite Solar Cells. J. Am. Chem. Soc. 2018, 140, 1019-1027.

[24] Mitzi, D. B.; Brock, P. Structure and Optical Properties of Several Organic-Inorganic Hybrids Containing CornerSharing Chains of Bismuth lodide Octahedra. Inorg. Chem. 2001, 40, 2096-2104. 
[25] Mousdis, G. A.; Papavassiliou, G. C.; Terzis, A.; Raptopoulou, C. P. Notizen: Preparation, Structures and Optical Properties of $\left.\mathrm{H}_{3} \mathrm{~N}\left(\mathrm{CH}_{2}\right)_{6} \mathrm{NH}_{3}\right] \mathrm{BiX}{ }_{5}(X=\mathrm{I}, \mathrm{Cl})$ and $\left[\mathrm{H}_{3} \mathrm{~N}\left(\mathrm{CH}_{2}\right)_{6} \mathrm{NH}_{3}\right] \mathrm{SbX} 5(X=\mathrm{I}, \mathrm{Br})$. Z. Naturforsch., B: J. Chem. Sci. 1998, 53, 927-932.

[26] Fabian, D. M.; Ardo, S. Hybrid organic-inorganic solar cells based on bismuth iodide and 1,6-hexanediammonium dication. J. Mater. Chem. A 2016, 4, 6837-6841.

[27] Zhang, W.; Tao, K.; Ji, C.; Sun, Z.; Han, S.; Zhang, J.; Wu, Z.; Luo, J. $\left(\mathrm{C}_{6} \mathrm{H}_{13} \mathrm{~N}\right)_{2} \mathrm{Bil}_{5}$ : A One-Dimensional Lead-Free Perovskite-Derivative Photoconductive Light Absorber. Inorg. Chem. 2018, 57, 4239-4243.

[28] Louvain, N.; Mercier, N.; Boucher, F. $\alpha$-to $\beta$-(dmes)Bil 5 (dmes = Dimethyl(2-ethylammonium)sulfonium Dication): Umbrella Reversal of Sulfonium in the Solid State and Short $|\cdots|$ Interchain Contacts-Crystal Structures, Optical Properties, and Theoretical Investigations of 1D lodobismuthates. Inorg. Chem. 2009, 48, 879-888.

[29] Kotov, V. Y.; Ilyukhin, A. B.; Korlyukov, A. A.; Smol'yakov, A. F.; Kozyukhin, S. A. Black hybrid iodobismuthate containing linear anionic chains. New J. Chem. 2018, 42, 6354-6363.

[30] Leblanc, N.; Mercier, N.; Allain, M.; Toma, O.; Auban-Senzier, P.; Pasquier, C. The motley family of polar compounds (MV) $\left[\mathrm{M}-\left(\mathrm{X}_{5-\mathrm{x}} \mathrm{X}_{\mathrm{x}}^{\prime}\right)\right]$ based on anionic chains of trans-connected $\mathrm{M}(\mathrm{III})\left(\mathrm{X}, \mathrm{X}^{\prime}\right)_{6}$ octahedra $(\mathrm{M}=\mathrm{Bi}, \mathrm{Sb} ; \mathrm{X}$, $X^{\prime}=\mathrm{Cl}, \mathrm{Br}, \mathrm{I}$ ) and methylviologen (MV) dications. J. Solid State Chem. 2012, 195, 140-148.

[31] Leblanc, N.; Mercier, N.; Zorina, L.; Simonov, S.; Auban-Senzier, P.; Pasquier, C. Large Spontaneous Polarization and Clear Hysteresis Loop of a Room-Temperature Hybrid Ferroelectric Based on Mixed-Halide $\left[\mathrm{Bil}_{3} \mathrm{Cl}_{2}\right] \mathrm{Polar}$ Chains and Methylviologen Dication. J. Am. Chem. Soc. 2011, 133, 14924-14927.

[32] Chen, Y.; Yang, Z.; Guo, C.-X.; Ni, C.-Y.; Ren, Z.-G.; Li, H.-X.; Lang, J.-P. lodine-Induced Solvothermal Formation of Viologen lodobismuthates. Eur. J. Inorg. Chem. 2010, 33, 5326-5333.

[33] Wang, Y.; Wen, R.; Liu, Y.; Bi, L.-Y.; Yang, M.; Sun, H.; Zheng, Y.-Z.; Zhang, G.; Gao, Z. Rigid Amine-Induced Pseudo3 D Lead-Free Bismuth Halide Perovskite with an Improved Band Edge for Visible-Light Absorption. ChemSusChem 2020, 13, 2753-2760.

[34] Soler, J. M.; Artacho, E.; Gale, J. D.; García, A.; Junquera, J.; Ordejón, P.; Sánchez-Portal, D. The SIESTA method for ab initio order-N materials simulation. J. Phys.: Condens. Matter 2002, 14, 2745-2779.

[35] Artacho, E.; Anglada, E.; Diéguez, O.; Gale, J. D.; García, A.; Junquera, J.; Martin, R. M.; Ordejón, P.; Pruneda, J. M.; Sánchez-Portal, D.; Soler, J. M. The SIESTA method; developments and applicability. J. Phys.: Condens. Matter 2008, 20, 064208.

[36] Dion, M.; Rydberg, H.; Schröder, E.; Langreth, D. C.; Lundqvist, B. I. Van der Waals Density Functional for General Geometries. Phys. Rev. Lett. 2004, 92, 246401.

[37] Cooper, V. R. Van der Waals Density Functional: An Appropriate Exchange Functional. Phys. Rev. B: Condens. Matter Mater. Phys. 2010, 81, 161104

[38] Cuadrado, R.; Cerdá, J. I. Fully Relativistic Pseudopotential Formalism Under an Atomic Orbital Basis: Spin-Orbit Splittings and Magnetic Anisotropies. J. Phys.: Condens. Matter 2012, 24, 086005.

[39] Zhang, Y.; Yang, W. Comment on "Generalized Gradient Approximation Made Simple. Phys. Rev. Lett. 1998, 80, 890.

[40] Troullier, N.; Martins, J. L. Efficient Pseudopotentials for Plane-Wave Calculations. Phys. Rev. B: Condens. Matter Mater. Phys. 1991, 43, 1993-2006.

[41] Artacho, E.; Sánchez-Portal, D.; Ordejón, P.; García, A.; Soler, J. M. Linear-Scaling Ab-Initio Calculations for Large and Complex Systems. Phys. Status Solidi B 1999, 215, 809-817.

[42] Krukau, A. V.; Vydrov, O. A.; Izmaylov, A. F.; Scuseria, G. E. Influence of the Exchange Screening Parameter on the Performance of Screened Hybrid Functionals. J. Chem. Phys. 2006, 125, 224106.

[43] Kresse, G.; Furthmüller, J. Efficient Iterative Schemes for Ab Initio Total-Energy Calculations Using a Plane-Wave Basis Set. Phys. Rev. B: Condens. Matter Mater. Phys. 1996, 54, 11169.

[44] Kresse, G.; Furthmüller, J. Efficiency of Ab-Initio Total Energy Calculations for Metals and Semiconductors Using a Plane-Wave Basis Set. Comput. Mater. Sci. 1996, 6, 15-50.

[45] Wilke, M.; Casati, N. Insight into the Mechanochemical Synthesis and Structural Evolution of Hybrid Organic-Inorganic Guanidinium Lead(II) lodides. Chem. Eur. J. 2018, 24, 17701-17711.

[46] Monk, P. M. S. The Viologens: Physicochemical Properties, Synthesis, and Application of the Salt of 4,4'Bipyridine; Wiley: New York, 1998.

[47] Leblanc, N. Ph.D. Thesis, University of Angers, Angers, France, 2011.

[48] Mercier, N. The Templating Effect and Photochemistry of Viologens in Halometalate Hybrid Crystals. Eur. J. Inorg. Chem. 2013, 19-31. 